\title{
Study on the Stratification of Web-based Learners
}

\author{
Zhang Zong-biao ${ }^{\mathrm{a}}$, Luo Lin-lin ${ }^{\mathrm{b}}$ \\ ${ }^{a}$ Modern Educational Technological Center, Zhejiang Shuren University Hangzhou, China \\ ${ }^{b}$ College of Information Science and Technology, Zhejiang Shuren University, Hangzhou, China
}

\begin{abstract}
This paper set out from the perspective of learning power, giving a comprehensive evaluation on learning ability and learning motivation with the fuzzy evaluating method, according to the different evaluation results, using the grid map to realize the Stratification of web-based learners. We have come one step closer to the improvement and perfection of an ideal individual network teaching.
\end{abstract}

Index Terms: Component; Learning power; Fuzzy evaluating; Stratification

(C) 2012 Published by MECS Publisher. Selection and/or peer review under responsibility of the International Conference on E-Business System and Education Technology

\section{Introduction}

The openness of network education undoubtedly provides a broader learning space for learners, and there is a growing focus on web-based learning. In this paper, network teaching platforms are emerging numerously. There are many teachers used to starting with the curriculum content, media networks, learning forms, methods, strategies, etc, but are not accustomed to catering from the perspective of learners. Probing to the reasons, it's the network education's special education environment and space separation that make it difficult for teachers to get web-based learners' dynamic learning and to carry out categories and levels of education, and then can not propose targeted measures to guide the learning. How to assess the study situation of the web-based learners, and how to stratify effectively; it has become an urgent problems we are eagerly to deal with.

Learning power refers to a comprehensive reflection of a person or an enterprise, an organization's learning motivation, perseverance and ability. As an effective way to train students' learning ability and standards to judge their learning ability, it has a potential impact on the learning activities, and is the determinants of high and low quality of learning [1, 2]. This article will analyze from the ability of learning, apply fuzzy comprehensive evaluation method, and conduct a classified and stratified study on web-based learners. 


\section{The Shought of Stratification}

\subsection{The basis of stratification}

Zhang Sheng-xiong thinks that:" Learning power contains three essential factors: learning motivation, learning perseverance, learning ability" $[3,4]$. In the web-based learning system, firstly, we find that two core elements must seized to stratification, that is, learning motivation and learning ability; Secondly, in specific learning areas, learning content and learning activities, we must seize learning perseverance, learning security forces and other auxiliary factors to stratification.

- Learning motivation is the fundamental factor to determine the learning behavior, learning orientation and learning levels. That is to say, the learners' internal needs are the reflections of their main values. If learners do not actively participate in the learning process, the process may be interrupted or stopped at any time. Learning systems evaluate their motivation for learning in mainly by the learner's attitudes, experiences and practices.

- Learning ability is the major constraint to determine the level of study, progress and learning outcomes. In the network learning systems, the web-based learners' comprehensive learning abilities are evaluated mainly through their test results and the testing process in the test database.

- Learning perseverance determines to learn deeper and more lasting. Just like learning guarantee and engagement, they are all protecting power of learning behavior, also the essential factors of learning victory. Therefore, in this article, we will not reflect this dimension.

\subsection{The method of constructing stratification system}

We are to put the learners' behavior data through fuzzy comprehensive evaluation method to calculate, quantify the learning ability and learning motivation of learners, classify them respectively into A1,A2,A3,A4,A5in five levels and B1,B2,B3,B4in four grades. Shown in Fig. 1, the lamination system which is formed by the dimensionality of learners 'study motility and study ability can be expressed by a cell chart, in this diagram, the horizontal axis represents learner motivation, vertical axis represents learner's learning ability. Horizontal axis is divided into four small cells, vertical axis is divided into five small cells, the first grid represents the lowest level, there are a total of 20 squares in the grid map, and each small square represents a hierarchical form.

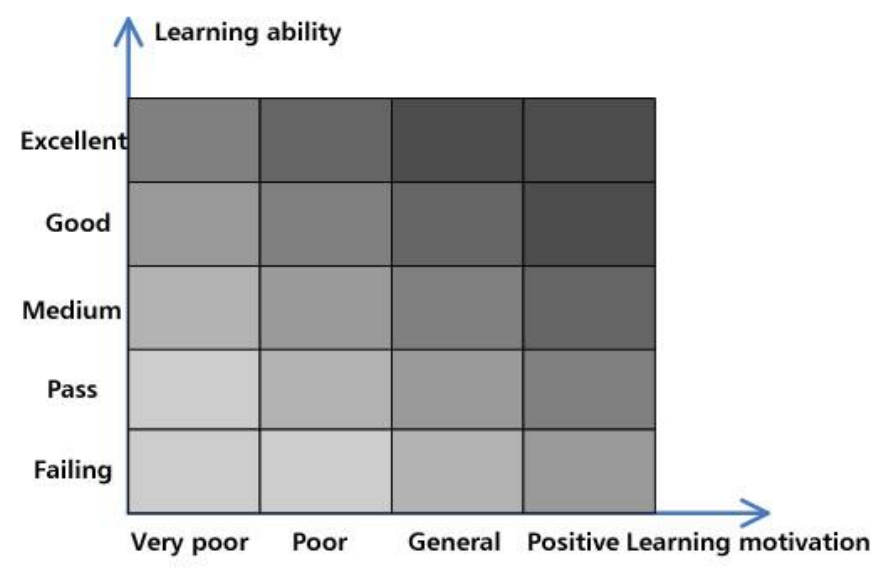

Fig. 1. The layered system of web-based learners 
Layered web-based learners are dynamic, multi-level, in teaching practice, will encounter this situation: Some students have strong self-learning ability, but the lack of intrinsic motivation, while others have the opposite. Speaking from the psychology of learning, the strength of learning motivation and the level of learning ability have a certain positive correlation, but not always the case. Thus, for learners of different levels of areas, teachers are required to provide the corresponding learning strategy guide, and encourage learners to move towards high-level degree.

\section{Method to Evaluate Learning Ability and Motivation}

\subsection{Fuzzy set theory}

Fuzzy set is a description of fuzzy concept, it is proposed by the famous American expert of control theory L.A.zadeh in 1965, the birth of fuzzy set theory to establish the theoretical basis of fuzzy problems.

Set $\mathrm{U}$ is a universe, $\mathrm{A}$ is the domain of a fuzzy set on $\mathrm{U}$, for any $u \in U$, are assigned a number $\mu(\mathrm{A})(\mu) \in[0,1]$ corresponding, $\mu(\mathrm{A})$ is called the membership of the A degree. This constitutes a map [5].

$$
\mathrm{A} \subseteq \mathrm{UA}=\left\{\frac{\mu_{\mathrm{A}}\left(\mathrm{U}_{\mathrm{i}}\right)}{\mathrm{U}_{\mathrm{i}}}\right\}, \mathrm{Ui} \in \mathrm{U} \mu(\mathrm{A}): \mathrm{U} \rightarrow[0,1]
$$

This map is called A's membership function.

\subsection{The expression of learning ability}

Learning ability is the major constraint to determine the level of study, progress and learning outcomes. Learning ability of learners in this article is measured mainly through its item bank in the testing process and test results. Referring to American educational psychologist Bloom's theory, we can draw assess student learning indicators: memory ability; comprehension ability; application ability; analysis ability; integrated ability; evaluation ability.

We put each knowledge point corresponding to the six indicators. For each exercise, there is a corresponding vector table, as shown in Table 1, vector table records the students' operationally learning ability corresponding subject right or not. Among them 1 means the right to use, 0 indicates not to use, -1 that using the wrong [6].

Table 1. Vector

\begin{tabular}{ccccccc}
\hline number & memorizing & comprehension & application & analysis & integration & evaluation \\
\hline NO.1 & 1 & 1 & -1 & 0 & 0 & -1 \\
NO.2 & 1 & 1 & 0 & 0 & -1 & -1 \\
\hline
\end{tabular}

In this way, we can define a six-vector to represent the student's learning ability:

$\mathrm{A}=(\mathrm{a} 1, \mathrm{a} 2, \mathrm{a} 3, \mathrm{a} 4, \mathrm{a} 5, \mathrm{a} 6)$, among them a $1=\{$ memory ability $\}, \mathrm{a} 2=\{$ comprehension ability $\}, \mathrm{a} 3=\{$ application ability $\}, a 4=\{$ analysis ability $\}, a 5=\{$ integrated ability $\}, a 6=\{$ evaluation ability $\}$. According to the above vector table can be calculated the use of learning ability of students to the correct rate $\mathrm{R}=(\mathrm{r} 1, \mathrm{r} 2, \mathrm{r} 3, \mathrm{r} 4, \mathrm{r} 5, \mathrm{r} 6)$, Among them $r i=\frac{e_{i}(1)}{e_{i}(1)+e_{i}(-1)}, i=\{1,2, \cdots, 6\}, \quad e_{i}(1)$ represents the first $i$ items ability to learn the proper use of the number of times, $e_{i}(-1)$ represents the first $i$ items ability to learn the wrong use of the number of times. 
This article on evaluation of learning ability of students is divided into five grades: A1; A2; A3; A4; A5, in which A1reprents 90 to 100 , A2 represents 80 to 89, A3 represents 70 to 79 , A4 represents 60 to 69 , A5 represents 60 below, so you can correspond to the five levels of subordinate function.

On $v 1=$ excellent: $\mu \mathrm{v} 1=\left\{\begin{array}{l}\frac{x-90}{10}, 90 \leq x \leq 100 \\ 0, x<90\end{array}\right.$

On $\mathrm{v} 2=$ good: $\mu \mathrm{v} 2=\left\{\begin{array}{l}1,90 \leq x \leq 100 \\ \frac{x-80}{10}, 80 \leq x<90 \\ 0, x<80\end{array}\right.$

On $\mathrm{v} 3=$ medium: $\mu \mathrm{v} 3=\left\{\begin{array}{l}1,80 \leq x \leq 100 \\ \frac{x-70}{10}, 70 \leq x<80 \\ 0, x<70\end{array}\right.$

On $\vee 4=$ pass: $\mu \mathrm{v} 4=\left\{\begin{array}{l}1,70 \leq x \leq 100 \\ \frac{x-60}{10}, 60 \leq x<70 \\ 0, x<60\end{array}\right.$

On v5=fail: $\mu v 5=\left\{\begin{array}{l}1,60 \leq x \leq 100 \\ 0, x<60\end{array}\right.$

Then through the subordinate function can be calculated moments of order $6 \times 5 \mathrm{M}=\left(\begin{array}{c}m_{11}, m_{12}, \cdots, m_{15} \\ \cdots \\ m_{61}, m_{62}, \cdots, m_{65}\end{array}\right)$, where mij represents the first $\mathrm{i}$ items corresponding to learning the value of $\mathrm{j}$-class membership, $\mathrm{i}=\{1,2, \ldots, 6\}$, Corresponding to that six learning ability, $\mathrm{j}=\mathrm{i}=\{1,2, \ldots, 5\}$, Corresponding to five levels of membership. In this way, we calculated $=\mathrm{R} \times \mathrm{M}=(\mathrm{r} 1, \mathrm{r} 2, \ldots, \mathrm{r} 6)\left(\begin{array}{c}m_{11}, m_{12}, \cdots, m_{15} \\ \cdots \\ m_{61}, m_{62}, \cdots, m_{65}\end{array}\right)=(\mathrm{v} 1, \mathrm{v} 2, \ldots, \mathrm{v} 6)$, then the vector $\mathrm{V}$ do normalized processing, this is what we want to get the membership. 


\subsection{The expression of learning motivation}

Learning motivation is the fundamental factor to determine the learning behavior, learning orientation and learning levels. In this article, the learners' motivation is measured mainly through its attitude, experience and practice in the learning platform. In order to reflect the evaluation of learners' motivation comprehensively, objectively and accurately, we follow certain rules to design the evaluation index system, index and the consistency of the target, indicators of completeness, independence, and testability and so on. According to these principles, then based on educational technology research methods on the evaluation order for each individual index split, "Power evaluation of learners table" is weighted designed, as shown in table 2.

Table 2. Learners' motivation evaluation form

\begin{tabular}{|c|c|c|}
\hline \multicolumn{2}{|r|}{ Index entries } & \multirow{2}{*}{ Weight } \\
\hline Primary indicators & Individuation indicators & \\
\hline \multirow{4}{*}{ Attitude } & Sense of participation and competition awareness & 0.07 \\
\hline & Actively collect information online & 0.05 \\
\hline & Take the initiative to come up with ideas and suggestions of inquiry content & 0.04 \\
\hline & Cooperate with each other happily & 0.04 \\
\hline \multirow{2}{*}{ Experience } & The requested records inquiry process and personal reflection & 0.05 \\
\hline & Can seriously timely complete the tasks assigned & 0.05 \\
\hline \multirow{2}{*}{ Practice } & Can learn the views of other students in the course of their work & 0.05 \\
\hline & Can provide ideas and share yourself findings & 0.05 \\
\hline
\end{tabular}

According to the evaluation table, giving groups $\mathrm{U}=\{\mathrm{u} 1, \mathrm{u} 2, \mathrm{u} 3\}, \mathrm{V}=\{$ Positive, General, Poor, Very poor $\}$, $\mathrm{W}=\{\mathrm{w} 1, \mathrm{w} 2, \ldots, \mathrm{wm}\}, \mathrm{U}$ stands for the aggregate composed of all the primary evaluation factors, $\mathrm{u} 1=$ attitude, $\mathrm{u} 2=$ Experience, $\mathrm{u} 3=$ Practice and $\mathrm{Ui}=\{\mathrm{x} 1, \mathrm{x} 2, \ldots, \mathrm{xm}\}$, it stands for the aggregate composed of all the secondary evaluation factors; V stands for the aggregate composed of all the remark grades; W stands for the aggregate composed of primary Weight $\left(\sum_{i}^{m} w_{i}=1\right)$, and $\mathrm{Wi}=\left\{\right.$ wi1 $\left.1, \mathrm{wi} 2, \ldots, \mathrm{w}_{\mathrm{ij}}\right\}$, it stands for the aggregate composed of secondary Weight $(\mathrm{i}=1, \ldots, \mathrm{m})$. Determine the membership function.

$$
\begin{aligned}
& \text { On } \mathrm{v}_{1}=\text { positive: } \mu \mathrm{v}_{1}=\left\{\begin{array}{l}
\frac{x-75}{10}, 75 \leq x \leq 100 \\
0, x<75
\end{array}\right. \\
& \text { On } \mathrm{v}_{2}=\text { general: } \mu_{\mathrm{v} 2}=\left\{\begin{array}{l}
1,75 \leq x \leq 100 \\
\frac{x-50}{10}, 50 \leq x<75 \\
0, x<50
\end{array}\right.
\end{aligned}
$$


On $\mathrm{v}_{3}=$ poor: $\mu_{\mathrm{v} 3}=\left\{\begin{array}{l}1,50 \leq x \leq 100 \\ \frac{x-25}{10}, 25 \leq x<50 \\ 0, x<25\end{array}\right.$

On $v_{4}=$ Very Poor: $\mu_{v 4}=\left\{\begin{array}{l}1,25 \leq x \leq 100 \\ 0, x<25\end{array}\right.$

Then through the subordinate function can be calculated $3 \times 4$ matrix of order $\mathrm{M}=\left(\begin{array}{l}m_{11}, m_{12}, m_{13}, m_{14} \\ m_{21}, m_{22}, m_{23}, m_{24} \\ m_{31}, m_{32}, m_{33}, m_{34}\end{array}\right)$,

Where $m_{i j}$ represents the first $\mathrm{i}$ items corresponding $\mathrm{j}$ level indicators motivation to learn the value of membership, $\mathrm{i}=\{1,2,3\}$, Corresponding to that three indicators of learning motivation, $\mathrm{j}=\mathrm{i}=\{1,2,3,4\}$, Corresponding to four levels of membership. In this way, we calculate $P=U \times M=(u 1, u 2, u 3)$ $\left(\begin{array}{l}m_{11}, m_{12}, m_{13}, m_{14} \\ m_{21}, m_{22}, m_{23}, m_{24} \\ m_{31}, m_{32}, m_{33}, m_{34}\end{array}\right)=(\mathrm{p} 1, \mathrm{p} 2, \mathrm{p} 3, \mathrm{p} 4)$, then the vector $\mathrm{P}$ do normalized processing, this is what we want to get the membership.

\section{Implementation of Stratification}

\subsection{Two-dimensional mathematical model of stratification system}

In the front of this article, mathematical model which is used to evaluate the learners learning ability and learning motivation is discussed in detail, but they are one-dimensional, click here to sort layered too simple to, not considering the relationship between the strength of learning motivation and the level of learning ability, therefore, We build the matrix shown in Fig. 2, through the evaluation of learning ability and motivation to learn can be calculated degree of membership of order $5 \times 4$ matrix $\mathrm{H}=(\mathrm{v} 1, \mathrm{v} 2, \ldots, \mathrm{v} 5) \mathrm{T} \times(\mathrm{p} 1, \mathrm{p} 2, \mathrm{p} 3, \mathrm{p} 4)=$ $\left(\begin{array}{l}v_{1} p_{1}, v_{1} p_{2}, v_{1} p_{3}, v_{1} p_{4} \\ v_{6} p_{1}, v_{6} p_{2}, v_{6} p_{3}, v_{6} p_{4}\end{array}\right)$ 


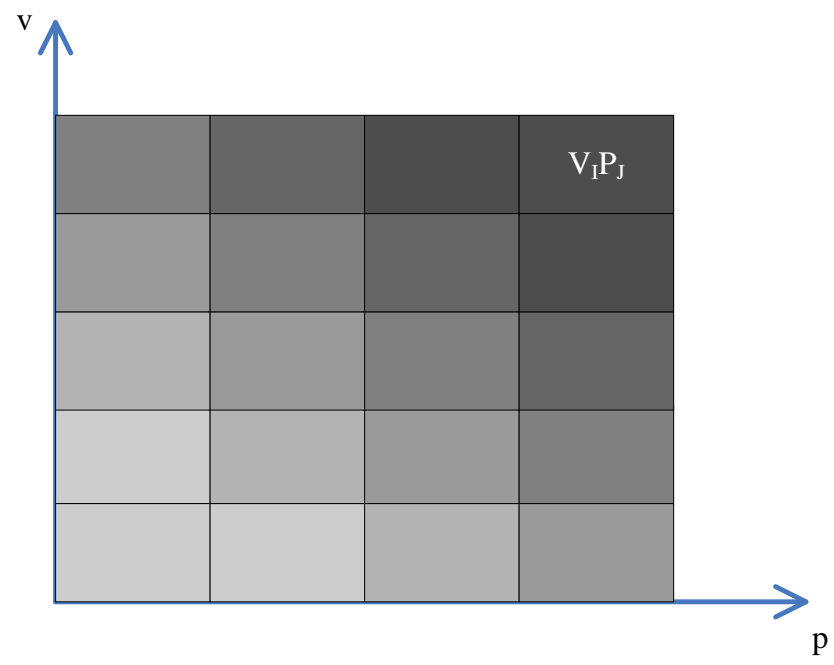

Fig. 2. Matrix

\subsection{The Guidance of stratification}

According to the learners' learning motions quantified in the model, learners can be divided into two kinds of mastery learning and the construction of learning and different learning tendencies of the study groups, and designs of two different learning tendencies Guidance program [7]. According to the model to quantify the ability of learners to learn the situation of these two types of learning can be further divided into task groups and task-oriented approach to learning assisted learning in two different groups.

Accordingly, to design four different levels of support services to fit the form of Guidance, one large capacity highly interactive learning process arrangements to fit study time, learning ability tend to have students construct learning; the second is high-capacity interactive learning process with low arrangements to fit a strong learning ability of students to master learning readiness; the third is small-capacity high-interactive learning process arrangements to fit the weak learning ability of students with constructivist learning orientation; Fourth is small volume of low interactive learning process arrangements to fit the weak learning ability of students.

\section{Conclusion}

This article is to classify and stratify the learners based on the perspective of learning power. According to this hierarchical system, the system can guide and help students' learning process on account of learner's learning ability and motivation, then finally meet the individual learning needs, and obtain very good results through the experiment.

\section{Acknowledgements}

This work has been supported by Zhejiang Province Emerging Artists Talent project.

Zhejiang Province Emerging Artists Talent project: Research and Realization on the Stratification of webbased learners. 


\section{References}

[1] Shen Shusheng,Yang Huan. Building Learning Power: A New Perspective of Education Technology Practice [J]. E-education Research,2009 (6):13-16.

[2] Chen Weiwei, Yang Huan. The Research Status and Development Trend of Learning Power in the Field of Education [J]. Open Education Research,2010 (2):40-46.

[3] Hu Zhijin. Classifying Distance Learners in Terms of Motivation, Aptitude and Perseverance [J]. Distance Education in China,2008 (1):34-41.

[4] Zhang Shengxiong. Build a Learning Organization[M].Beijing:Shanghai Popular Science Press,2008.

[5] He Guoqiang, Liu Lizhen, Du Chao. Design of student model in intelligent learning system [J]. Computer Engineering and Design,2009(10):2554-2557.

[6] Zhang Zhiqin. Research on the Student Model Based on Neural Fuzzy Comprehensive Method [D].Wuhan: WuHan University Of Technology,2006.

[7] Hu Zhijin. On the Guidance of two different tendencies design [J]. Distance Education in China, 2007 (10) :34-39. 